\title{
The Study of Proverbs from Perspective of Intercultural Analysis
}

\author{
Stepan Grabski \\ Armenian State Pedagogical University after Khachatur Abovyan \\ Armenia
}

\begin{abstract}
This aim of this study is to analyze the Spanish sayings and proverbs from the perspective of the methodology of teaching of the phraseological units of Spanish in the Armenian auditorium. The point of view of our analysis is the relevant presentation of proverbs - as units of cultural branding - in classes of Spanish as a foreign language based on the philosophy of intercultural communication. The respective classes are presented with an emphasis on exercises designed to develop the communicative flexibility as well as linguistic skills.
\end{abstract}

\section{Introduction}

The main purpose of this investigation is to prove that proverbs are very efficient tools for teaching foreign languages and that proverbs are also very versatile to convey sufficient cultural information to increase the overall intercultural awareness of the students. The present study has two more specific purposes: (1) to illustrate the convergences and divergences in the sayings and proverbial system both in Spanish and in Armenian, (2) to study, in a more analytical way, the quantitative and qualitative properties of proverbs with the intention of offering more or less fixed dimensions on how to plan and structure the teaching during the process of acquisition Spanish as a foreign language. The comparison of these fixed units, more precisely, the search for equivalents and their investigation in situationally relevant contexts, is a more than appropriate method to facilitate the process of acquisition of foreign languages and the formation of a certain level of the paradigm of intercultural values.

And we wanted to stress that though foreign language teachers underestimate the role of proverbs for forming intercultural competence and teaching a language, designing well-thought materials or exercises may help them during foreign language classes. For us represented a special and profound interest as to how efficiently proverbs can be used to increase one's vocabulary and the intercultural awareness of the students during the communication, as well as to discover the exact relation. The comparison of these units will allow us to draw certain conclusions that have both cultural and linguistic values.

\section{Theoretical framework}

The theoretical basis of the research has been selected according to the criterion of the perspectives of intercultural communication to reveal how the learning of the phraseological units encourages communication skills at various levels of progress. And precisely for that reason, there are authors, among which we may find the interesting researches of Margarita Koszla-Szymanska on that topic [1].

The most interesting theoretical aspects of our research we consider:

- For the first time, we compare Spanish and Armenian proverbs (there is no known similar study done up to now).

- We believe that cultural and linguistic comparison of proverbs contributes to foreign language teaching and acquisition.

- Armenia and Spain are too far geographically to prove the effectiveness of cultural and linguistic teaching of proverbs.

- We believe this research is useful for developing intercultural competencies.

The traditions related to the proverbs and the idiomatic patterns with numerical terms are very common in folklore and, from this perspective, it is interesting and extremely useful to study them and observe how they manifest themselves in different oral and written traditions and cultural contexts. Proverbs offer unique possibilities to deepen beliefs, rites, traditions and the innumerable cultural riches of each nation. The proverbs also continue to hold and fix the beliefs and superstitions accepted in the traditions of the people.

It would be worth to mention how exactly we define the word "proverb", so we may stress that proverb is a saying that expresses a common truth. It deals with the truth simply and concretely and teaches the listener a lesson. It can help to understand a culture and can help to determine if it is a group- or individual-oriented culture. It may also help in understanding what is desired and undesired as well 
as what is considered correct or incorrect in the given culture [2]. Also, it was very important to stress that the specific character of proverbs and sayings relates to the tradition of the determined linguistic society. The usage of such conventional lexical connections during the teaching of a foreign language doesn't solely assure the communicative and cultural competency but also forms the reflection of customs and traditions of humans of the given country [3].

\section{Methods}

We developed a rather exact methodology of examining the students. Those were questionnaires designed to examine the amount of vocabulary, as well as how much students had learned by reading the proverbs we gave to them.

As we want to prove that proverbs are efficient for:

- Foreign language teaching,

- Increasing intercultural awareness of the students

So, we decided to make exercises alongside with questionnaires to:

1. Increase student's foreign language knowledge, namely, vocabulary size. Because this study will be carried out in Armenia, all our students are Armenians who study Spanish as a foreign language, we think that proverbial comparison charts will serve very well for such purpose.

2. We also plan to question Spanish language professors and teachers just to reveal how they would evaluate the progress.

3. The evaluation will be carried out with the help of exercises.

The exercises are rather voluminous: they included comparison charts with more than 1000 proverbs in Spanish alongside their Armenian equivalents (with numerals). So, we may stress some of the most important points of this research where (1) the exercises we designed are meant to evaluate both the language learning and the vocabulary acquisition and (2) These exercises were also designed to evaluate statistically one's cultural acquisition (which means how much students learned the meanings literally or allegorically transferred by proverbs). Exercises were split into corresponding parts that were equal in both Armenian and Spanish. In these kinds of exercises, we used the comparative and the contrastive methods using both Armenian and Spanish language.

Contrastive chart example:

$$
\begin{aligned}
& \text { Uh hutippn цшum, Más ven cuatro ojos que } \\
& \text { tinlnoun' } m u t_{L} h \text { : dos }
\end{aligned}
$$

The literal meaning of this proverb is that "Two minds are better than one"(two people working together are more efficient than one): As we see the point of this exercise is that by comparing the meaning in the Armenian proverb, student deduces the corresponding Spanish word. The main difficulty for us was the matching of the proverb's exact meanings.

And so, we continued with a similar series of meanings (reaching up to 1000 samples, this amount is senseless to be shown entirely here):

\begin{tabular}{|c|c|}
\hline $\begin{array}{l}\text { Habla poco, escucha más, } \\
\text { y no errarás. }\end{array}$ & Util hunut, unuu jut \\
\hline $\begin{array}{l}\text { A quien tanto ve, con un } \\
\text { ojo le basta. }\end{array}$ & 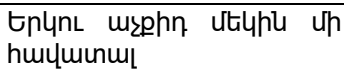 \\
\hline La mentira no tiene pies & $\begin{array}{l}\text { Zuqum unsun Jitl nnnn } \\
\text { zundtin }\end{array}$ \\
\hline Una mentira, de ciento tira & $\begin{array}{l}\text { Zuqum unLun Util nnnn } \\
\text { zwattn }\end{array}$ \\
\hline
\end{tabular}

Table 1. Contrastive chart [5], [4].

Table 2. Their meanings in English

\begin{tabular}{|l|l|}
\hline $\begin{array}{l}\text { Speak few, hear more and } \\
\text { You will not err. }\end{array}$ & Speak one, hear ten. \\
\hline $\begin{array}{l}\text { For who watches too } \\
\text { much, one eye is enough. }\end{array}$ & $\begin{array}{l}\text { Don't believe only to one } \\
\text { of your eyes }\end{array}$ \\
\hline A lie has no feet & $\begin{array}{l}\text { Thousand lies valued } \\
\text { nothing }\end{array}$ \\
\hline $\begin{array}{l}\text { One lie, hundreds of } \\
\text { shoots }\end{array}$ & $\begin{array}{l}\text { Thousand lies cost not } \\
\text { even a single word }\end{array}$ \\
\hline
\end{tabular}

The exercises are led by similar principles. Our goal is to accumulate enough statistical data for further analysis.

\section{Results}

We examined more than 1000 proverbs in both languages. To our surprise, there is great concordance in meanings in both these languages (Armenian and Spanish) The origins of this similarity is profound and needs some deep scientific explanation. If we generalize our results and sum up the main results of our analysis, it is important to stress that comparison of the proverbs was one of our main goals of the study, then it becomes clear that we had mainly two similarities:

1. Complete semantic similarities (where meanings corresponded)

2. Complete or semi-complete typological similarities (where both the separate words and the meanings corresponded)

\subsection{The total correspondence}

We studied more than 6000 Spanish proverbs and more than 5000 proverbs in Armenian separately. We chose 1000 proverbs from both languages and compared them. We compared them by the criteria of semantic correspondence and by typological correspondence (complete or semi-complete). 


\subsection{Semantic and typological correspon- dence}

- By semantic correspondence, we presume that the meaning of proverbs of both languages is (more or less) the same.

- By typological correspondence we understand that separate words or expressions within the proverbs correspond and express the same meaning

Examples of typological correspondence:

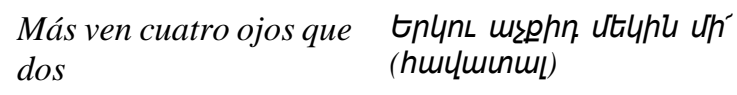

Their equivalents in English:

$$
\begin{array}{ll}
\begin{array}{l}
\text { Four eyes see more than } \\
\text { two }
\end{array} & \begin{array}{l}
\text { Don't believe your two } \\
\text { eyes }
\end{array}
\end{array}
$$

As we see here we have a semi correspondence by the words "two" or "eyes"

Examples of semantic correspondence:

$\begin{array}{ll}\text { Entiende primero y } & \text { Zuqun hunuphu uttl } \\ \text { habla postrero. } & \text { hunup, huqun } \\ & \text { Glónnıl Utly pun }\end{array}$

Their equivalents in English:

$\begin{array}{ll}\text { Understand first and } & \text { To thousands of words- } \\ \text { then speak } & \text { one word, to thousands } \\ \text { sparros - one stone }\end{array}$

In these two examples, we see clearly how the same meaning is expressed in completely different ways without a single coincidence of a word.

And all the proverbs were similar in this twofold way either by semantic or (rarely) by completetypological correspondence, where one or more words are the same, or by semantic correspondence where only the meaning is the same.

Further analysis of these quantities led us to some extensive and voluminous conclusions.

\section{What topics were typically common (thematic correspondence)}

These three topics were the most commonly used ones, because (as we suspect) they are common in any culture's proverbial system.

\section{Money $(21,90 \%)$ \\ 2. Farming (21,90) \\ 3. Human Intrigues $(15,33 \%)$}

We also made a general list of topics and their corresponding percentage rates. We believe those are important from the intercultural analysis. The studies we have carried out, allowed us to locate certain constants in our studies. These data have some statistical significance that needs profound interpretations and some comments. We think that these will offer certain general considerations that can be applied within different thematic fields different from those of our study. We have to emphasize that although our work does not collect all the proverbs (with or without numeral components) it does include the vast majority of them as it is based on the most elaborate Armenian proverbial compilations and also the most recent Spanish ones. We decided to analyze the quantitative aspects of the proverbs and, besides, the thematic features regarding the statistics of the coincidences between Armenian and Spanish proverbs that appear in certain times and in certain times they don't. The conclusions we have reached after the statistical analysis of the proverbs are very deep. We have more than 1000 proverbs, without taking into account the coincidences and, besides, 653 proverbs considering the coincidences between the Armenian and Spanish proverbs. For us, the quantity and value of proverbs that were more frequent represented an interest, and we were also interested in the thematic field to which those proverbs belonged and what percentage they made up of the totality of the proverbial collections we analyzed and studied. When talking about the numerals and without taking into account the coincidences, the quantity of the proverbs that contain numerals is more abundant in Spanish, than in Armenian, 417, which forms 41.7\% of the same total amount. This fact is quite interesting because it seems that these differences are more related to, perhaps, the fact that the Spanish proverbs are more numerous in their quantity than the Armenian ones (this at least proves our analysis of the proverbial collections that served as sources of the study for our work). If we talk about concrete proverbs that include numerals, then in both languages the values of the most common numerals are one (1) and two (2). These two numerals form $53.5 \%(27.80 \%$ for numeral 1 , and $25.70 \%$ for numeral 2) of the total amount of the proverbs with numeral components that we registered in the Spanish collections. In the case of Armenian, the situation is quite similar although this time the exact amounts that we consider are a little different. In Armenian proverbs, the total number of numerals one (1) and two (2) form $68.31 \% \quad(41.05 \%$ and $26.2 \%$ respectively). The next most frequent numerals we can find is the thousand (1000) numeral. These numerals form $4.44 \%$ of the total in Spanish and the thousand numeral forms about $13.1 \%$ of the total amount of the proverbs found in this language. Then comes the number one hundred (100) found in $9.13 \%$ and $2.18 \%$ of the cases respectively. And then we finish the list of the most frequent proverbs with the numeral ten (10) $(3.51 \%$ and $1.79 \%$ respectively) and the numeral seven (7) with $2.10 \%$ and $1.35 \%$. We must also talk about the numerals that do exist in Spanish, but do not exist in Armenian and vice versa. Among these numerals, it is worth highlighting the 
numeral 9 that was not found in Spanish but we found it in Armenian proverbs with a $1.33 \%$ frequency, then it is necessary to mention the numeral twelve, so, it is quite common in Armenian with $1.78 \%$ of frequency but we could not detect it in the corpus of Spanish proverbs. Numeral twelve if used quite frequently in Armenian proverbs and this fact has a fairly logical explanation. Then comes the number fifty, sixty, seventy and eighty that were not registered in the Armenian proverbs (at least in the proverbs that we use), but appear with certain frequencies $(0.23 \%$, $0.46 \%, 0.46 \%$, and $0.23 \%$ respectively). It is quite interesting to find the explanation of why these proverbs were not so frequent, but perhaps we can relate this to the fact that these numerals talk about the topic "age" and Armenian proverbs are more different regarding these questions. It is curious to mention also the appearance of the numeral five hundred in Armenian with $0.44 \%$ frequency and that practice was not found in Spanish. The same happens with the numeral million $(1,000,000)$ that appeared in Spanish and that (as we suspect) does not exist in Armenian. If we talk about the topics, that is, the number of proverbs carried by each topic presented in our analysis list, then we can underline the almost uniform distribution of the topics, although, of course, there are exceptions. If we consider the Armenian list of proverbs, $19.01 \%$ of the proverbs belong to the theme that speaks of "sadness and joy." These two themes seem to be very common and reflect well the states that human beings experience during their lives. The other $19.01 \%$ belong to the topic "who must rely on their strength". The dominance of such a percentage is not surprising since we talk about the problems faced by human beings throughout their lives. So, "trusting your strength" is a fairly common matter since it tells us how normally a human being treats the other. These two proverbs together form $38.02 \%$ of the total list. The other $14.11 \%$ is divided between the proverbs that speak of "changes", "dignity" and infidelity respectively. "Infidelity and ambition" are very common topics, but it is not very clear because they take the second place in the list of the most frequent proverbs, perhaps because they talk about the qualities that can cause "problems" of antisocial origin. The third place, $10.56 \%$, is divided between the proverbs that speak of "success and failure", of "drones and robbery" and also "of the people who are always not at ease". Each topic of these three has a frequency of $3.52 \%$. It is also worth noting the less common themes, these six themes that speak of "honesty", "misfortune", "uselessness", "intrigue" and "identity" with $0.72 \%$ frequency for each one respectively. If we talk about Spanish topics, the three most common and prominent topics are those that talk about "intrigues", "agricultural work" and also lately about money which sounds quite logical because the money problem has occupied human beings for centuries. These three proverbs form $59.13 \%$ (with $21.90 \%, 21.90 \%$ and $15.33 \%$ respectively). It is quite interesting to compare these three quantities with the statistical data of the Armenian proverbs because here very interesting and worthy cultural factors stand out for even more detailed studies. The next four most frequent topics on the list of Spanish proverbs are the following: "ambition" with $8.02 \%$ frequency, "misfortune and arrogance" with $6.56 \%$ frequency and this list concludes two other proverbs that speak of "family" and being "brief and direct" with the following statistical data: $5.84 \%$ and $5.10 \%$ respectively. The following 9 topics have the poorest statistical frequency are: "trust in your own strength" $(0.73 \%)$, "shameless" $(0.73 \%)$, "from bad to worse" $(0.73 \%)$, "Trust their own strength" $(0.73 \%)$, "everything has its price" $(0.73 \%)$, "the wise and the fool" (0.73\%), "sadness and joy" (0.73\%), "truthfulness and truthfulness" $(0.73 \%)$, "adequate and dignified" $(0.73 \%)$, "discreet and careful" $(0.73 \%)$, "Honest and dishonest" (0.72\%), "social inequality and injustice", "incompetent and useless" $(0.72 \%)$. It is very interesting that in both cultures the list of proverbs has a certain regularity that is universal for both. Of course, many differences have interesting properties. So, we believe, this study can be extended.

\section{Conclusion}

This comparison allows us to conclude that by studying proverbs students can begin to discover the cultural values that are expressed in the language they study. Besides, the analysis of phraseological units based on the selection of proverbs with a certain component or certain theme can contribute to the development of the methodology of teaching foreign languages, in particular, from the perspective of intercultural analysis.

\section{References}

[1] Koszla-Szymanska, Margarita Los fraseologismos, dichos y frases hechas y su importancia comunicativa en la enseñanza del español como lengua extranjera. Catedral de Estudios Ibéricos, Universidad de Varsovia, Warsaw, 2005.

[2] Buitrago Jiménez, Alberto. "Diccionario de dichos y frases hechas”, ESPASA CALPE, Madrid, 1996.

[3] Casares, Julio. Diccionario ideológico de Ia lengua española. Barcelona, Gustavo Gili, Madrid, 1989.

[4] Ghanalanian, A. Proverbs, Luys, Yereván. 1960.

[5] Iribarren, José María, El porqué de dichos, Pamplona. Gobierno de Navarra, 1997.

[6] Hui-Chih Yu. A Comparative Study of the Meanings of Numbers in English and Chinese Cultures, Shih Hsin University, 2015. 